\title{
Online Education: Issues, Challenges and Implications
}

\author{
OLATUNJI, Michael Olalekan \\ Institute of Educational Leadership, Gaborone, Botswana
}

\section{INTRODUCTION}

Due to the rapid adoption of electronic communication and media, many educational institutions are delivering a large portion of their classes and curricula online. It is predicted that online course enrolments will continue to grow in all sectors of education (Allen \& Seaman, 2008). According to Ebersole (2007), in a society where people are changing jobs and careers more frequently, while simultaneously raising families, online learning is emerging as one essential and sensible alternative. The University of Phoenix, Online campus has the highest enrolment of students in the United States with over 224,000 students (National Centre for Educational Statistics, 2009). Over $90 \%$ of higher education institutions in the United States offer Internet courses (Callopy \& Arnold, 2009). Online learning has increased in popularity with both institutions and students not only in the United States but around the globe. This is because students find it more convenient to take classes online without the expense and time constraints involved with commuting to a campus facility. Furthermore Institution administrators see online teaching as a significant means of generating more money. In addition, Institutions can reach out to more students without necessarily employing additional staff or increasing physical space. Online students are not just adults aiming to bring about professional development but also young people desiring same. This fact has aroused the interest of a large number of institutions, which offer courses in the form of blended learning models or totally online. These alternatives offer flexible and choice options that are more and more adaptable to the objectives and interest of students of all ages and cultures who live anywhere in the world. However, as online learning continues to alter the educational landscape, new issues confront instructors and students (Capra, 2011). Despite the emerging challenges associated with online learning, students demand for this flexible learning environment continues to rise (Allen \& Seamen, 2008). It has been predicted that this surge will not stop but will rather continue to rise because of such factors as the cost of transportation 
which continue to skyrocket therefore making learning from home more advantageous (Allen \& Seaman, 2008).

In the light of this interesting paradox; growing demand and enrolment coupled with increasing issues and challenges, this paper examines on-line education in its pure form as distinct from the blended form, with particular focus on some emerging issues and challenges. The implications of these issues and challenges are also discussed.

\section{Some Emanating Issues and Challenges}

Online educators are faced with a number of situations when teaching an online learning class as opposed to a traditional class. These include: the administration of online courses, the course layout and design, the best delivery method for content (such as, text, graphics, audio, or video), ways to increase and maintain student involvement, a working knowledge of modern technologies, comprehensive assessment methods, balancing the goal of learner centeredness and learner responsibility with the need to keep discussions focused on the intended learning outcomes.

These aforementioned situations among others, call for expertise meant to be acquired through Teacher Education program. A major challenge however is that while some universities and colleges have established training programs to prepare their online educators to teach online, many institutions do not have such programs in place. For example, Talent, Copper, Lan, Thomas \& Bushy (2005) reported that without necessary preparatory training, many online educators were encouraged to teach courses online. Shepherd (2008) observed also that online educators are simply told they will have to teach online, and have to self educate with manuals

Suffice it to say that the specialized skills which online teaching in the real sense of the word requires are not acquired that easily if effectiveness would not be compromised. Ducan \& Barnet (2009) pointed out that online teachers tend to work in isolation and because of this there are limited opportunities for reflection and sharing of best practices. Incidentally, the skills needed to teach online cannot be acquired just on the job by using one's intuition, granted that the skills could be improved upon on the job but there must be that initial comprehensive training and education acquired formally.

Gibbs \& Coffey (2004) carried out a quantitative study in which they examined the impact of training of university teachers on teaching skills and students' approach to learning. A training group of teachers and their students were studied at the beginning of the teacher training and one year later, the training group became less teacher centered and more students centered by the end of four to eighteen months. In addition, their teaching skills improved significantly after the training as judged by 
students. This study underscores the importance of in-depth initial professional training for online teachers.

Before the advent of online education and the revolution it ushers into education, teaching in many countries has remained classified as a semi profession. This is unlike law, medicine, engineering etc that have for years remained classified as full fledged professions. The argument all along has rightly been that teaching in many countries does not possess all the characteristic of a full profession. Ornstein \& Levine (2003), Ingersoll and Perda (2008) identified some of the most widely used indicators of professions and professionals. These include:

- A sense of public service-a life time commitment to a career

- A defined body of knowledge and skills beyond that grasped by laypersons

- A lengthy period of specialized training

- Control over licensing standard and / or entry requirements

- Autonomy in making decisions about selected spheres of work

- An acceptance of responsibility for judgments made and acts performed related to services rendered; a set of standard of performance

- A self-governing organization composed of members of the profession

- Professional association and or elite groups to provide recognition for individual achievements

- A code of ethics to keep help clarify ambiguous matters or doubtful points to services rendered

- High prestige and economic standing.

The challenge here is that the problems that plagued teaching and which for ages have kept it from becoming a full fledged profession and from being seen and treated as such by the public before the introduction of the much celebrated online education, are now becoming part and parcel of this relatively new system despite its glamour. This is evident among other things by the professional status of online teachers in various countries that range from those with specialized professional training in online teaching, those with both specialized training in on-line teaching and classroom teaching, those with professional training in classroom teaching alone, those with mere skeletal training in online teaching acquired through few days of conference/ workshop attendance and those without any professional training at all.

Where the only training received by online educators is just limited to occasional workshops attended, casual mentoring by colleagues and ideas gathered from books, the implication is that it is very difficult to guarantee that students studying online are in safe hands with respect to the soundness of the pedagogy being employed by online teachers. 
A further implication of this unwholesome situation is that the professionalization of teaching may become increasingly elusive in many countries unless there is a timely intervention to ensure that the laxity that turned in-class teaching into an all comers affairs will not also become a permanent feature of online teaching. Bonnet (2007) revealed that teaching is a mass occupation and that this has continued to militate against "professional" exclusivity. The teaching fraternity especially in most countries accommodates both those who are professionally trained and those who are not. To confirm his observation, Bonnet points out that in Chad, $61 \%$ of the teachers are contract teachers and this category is not required to complete pre-service training. Mali, Mauritania and Togo all have significant part of all teachers who received a very short training of 1 to 3 months. Despite the existence of the very short training, more than half of the teachers in Togo for instance have no professional training at all(Bonnet 2007). Such is the confusion that has been going on in the conventional teaching industry for years in many countries. Incidentally, this confusion is gradually creeping into online teaching.

Shepherd (2008) observed that online educators want people who have had experience in teaching online courses to share their best practices. He suggested that online educators who are competent in the technology process can mentor others in their department and that educators would like to be able to ask a colleague to drop by for quick assistance with teaching online. Shepherd maintained further that clearly, one on- one mentoring is the technological training choice among online educators at institutions of higher education and that it is the key to increasing the efficacy of educators teaching online. However, while one-on- one mentoring is undeniably a good way of increasing the efficacy of online teachers, the idea of dropping by for quick mentoring or piece meal mentoring even when carried out on one- on -one basis can not and should not replace the necessary initial in-depth professional training. The fact that many online teachers have been functioning simply on the basis of mentoring that they derived from personal visits shows how removed the skills that many online teachers have been functioning with are from the skills they ought to be functioning with and the extent to which teaching could be "trivialized and made so easy"

The implication of making do with "casual training" for online teaching can be far reaching as it goes a long way to affect the status of online educators themselves as a people involved in such a system where the training needed can be acquired at the press of the button. For online education as a system, such practice has a diminishing effect on its status and credibility. According to a report carried out by Keengwe, Kidd \& Kye-Blackson (2009), online educators felt additional instructional and technical support were needed because they were genuinely concerned about the quality of their online courses and the training available to them at their institutions. One observes that 
the prevailing situation is still significantly the same in many institutions offering online programs.

Furthermore, Reeves (2006) pointed out that the success of any learning environment, including e-learning, is determined by the degree to which there is adequate alignment among eight critical factors: 1) goals, 2) content, 3) instructional design, 4) learner task, 5) instructional roles, 6) student roles, 7) technological affordability, 8) assessment. However, Reeves and Hedberg (2003) highlighted the fact that the evaluations of traditional, online, and blended approaches to teaching indicate that the most commonly misaligned factor is assessment. Similarly, Robles and Braathen (2002) observed that although educators at all levels have embraced using online technology as a teaching tool, the issue of assessment of student learning has not been thoroughly addressed. As a confirmation of the fact that the observations of Reeves and Hedberg (2003) and that of Robles and Braathen (2002) are still relevant, Sperber (2005) argued that it is very clear that most instruction in higher education is focused on the cognitive domain to the exclusion of the affective domain. Saxon and Calderwood (2008) also pointed out that practically most assessments done in the United States Colleges and Universities are cognitive.

The cognitive domain is concerned with objectives involving intellectual activities ranging from remembering and applying to analyzing, synthesizing and evaluating. The affective domain deals with objectives involving emotions or a degree of acceptance or rejection, which may be expressed as interests, attitudes and values.

While in-class education's neglect of the affective domain has been there for years, a major issue is how to ensure that this aversion does not become part and parcel of online education. The provision of holistic assessment that will give the affective domain the needed and sufficient attention is the ideal for any educational program including online education. Ensuring this in online education is however a challenge.

There are numerous factors that contribute to higher education's collective neglect of the affective domain (Pierre \& Oughton, 2007). A school of thought opines that affective learning is a by-product of cognitive learning and for this reason it is argued that affective learning outcomes do not need to be indicated, taught, or assessed separately. Furthermore it is maintained that there are in fact, close parallels between Bloom's taxonomy for the cognitive domain and Krathwohl's taxonomy for the affective domain (Smith \& Regan, 1999) and because of this, special attention should not be give to the affective domain. Further challenges in affective learning and assessment is said to arise from difficulties in precisely stating desired affective learning outcomes because they involve opinions, beliefs, and attitudes (Bloom, Engelhart, Furst, Hill \&Krathwohl 1956; Smith and Regan, 1999). 
Yet another School of thought that seeks to explain the lack of attention given to the affective domain maintains that the domain is intuitive and for this reason, it is better at the university to concentrate on the body of knowledge that will enable students to develop problem solving skills, critically question science and society and demonstrate the capacity to develop creative response to difficult and complex problems (Krathwohl et al, 1964; Pierre \& Oughton, 2007). It is also argued that the cognitive domain is relatively easy to assess and to apply sound assessment practices like moderation to ensure some level of objectivity and fairness (Pierre \& Oughton, 2007). On the other hand the affective domain is said to be contentious, raising all manner of fundamental challenges and questions that go to the very heart of the purpose of education at a tertiary level and asks hard questions about social and cultural power in education, such as:

- How does one judge intrinsic qualities such as values, motivation, feelings and attitudes?

- Is higher education an appropriate place to develop qualities such as hard work or having a goal?

- If so how should they be assessed?

- What will be used as a standard upon which one judges?

- How does one ensure any sense of validity and transparency?

- How can one tell if students are authentically displaying these intrinsic traits and not just "playing the game"? (Birbeck. \& Andre ( 2009)

Plausible as these arguments may be or seem to be, one opines that they do not justify the apathy concerning affective education and its assessment in online education. According to Stiggins (2005, p.199 - 200), "motivation and desire represent the very foundation of learning. If students do not want to learn, there will be no learning. Desire and motivation are not academic achievement characteristics, they are affective characteristics". This being the case, the only avenue of working on learners' desire and motivation has long remained unattended to in online education. Nolting (2007) pointed out that performance in Mathematics has almost as much to do with students' attitudes and beliefs as it has to do with their mathematical knowledge. Mathematics and the Sciences have for many years been seen as dreaded areas by many in-class and online students and the situation is still the same. Similarly, Capra (2011) also observed that Higher Education is struggling with increase of student withdrawal and failure rates in online courses. This is one of the implications of the aversion of teaching and assessing affective characteristics in online education. 
At all levels of online education there is the possibility for the level of interest in learning and the desire to excel academically to diminish over time. While some learners do drop out of online education program for inability to see the relevance in the curriculum, some of those who succeeded in completing the program do end up totally disengaged from the educational process for the same reason. Institutions of higher learning, particularly community colleges report that withdrawal rates in online courses have surpassed traditional courses by at least 20\% (Aragon \& Johnson, 2008). This is also an implication of the absence of teaching and assessment of affective characteristics embedded in the curriculum. Such assessment if put in place would enable online educators to keep regular watch on students' beliefs concerning their ability to meet educational objectives and standards as well as the students' attitudes concerning the relevance and importance of the content they are learning. Affective construct therefore puts the online educator in a good position to identify on time students with the likelihood of dropping out of the program. Since not much use is being made of the affective construct, a lot of casualties continue to be recorded by way of learners dropping out of online education program or losing interest after completing a segment of the program successfully.

Popham, (2011, p.233) argued that the reason such affective variables such as students' attitudes, interest and values are important is because they typically influence future behavior. He highlighted further that it is necessary to promote positive attitudes towards learning because students who have positive attitudes towards learning today will be inclined to pursue learning in the future. It follows therefore that where the machinery through which the affective status of online learners can be known and monitored are not put in place, it becomes practically impossible to know how such learners are predisposed to behave in subsequent years. This is the prevailing scenario within online education system and the implication of this is that the online learners who would have been helped while still within the system lost the opportunity because there was no way of knowing their affective status.

Ideally, Education is to equip the learner for citizenship and citizenship precludes an individual who is not just able to read, write, carry out mathematical operations, think critically, be an effective employee or employer but also possess a general sense of social responsibility. However, for some years now, looking at those graduating from online education program, a learner with pass marks in his or her course/program of study receives a certificate at the end of the course no matter how "unruly" he or she may be. This is all because the affective traits do not count towards obtaining a certificate. Apart from the certificate that shows academic attainment, Institutions operating online programs do not issue any document that shows affective characteristics and such document with Institutional authentication is not required in the job market either. Herein lays the root of "moral decay", as a good number of 
online learners are turning out to remain "amoral" as they graduate from online education program.

Griffith \& Nguyen (2006) rightly liken the cognitive domain when focused upon alone in the curriculum at the expense of the affective domain to a skeleton without the skin. Strangely enough that is what the curriculum of online education has continued to be for years. Olubor \& Ogonor (2007) carried out a study that hinges on production theory. The crux of the theory is that within a learning environment, if the change agents adequately process the inputs into the system the desired output can be attained. In online education, the educators and the learners are both the inputs while the online educators are also the main agents in the processing stage. The ability of the online educators to successfully carry out the processing stage diligently, determines the expected output which in the study is the good citizen. They however submit that citizenship education can best be taught by using teaching methods in the affective domain. They correctly observe that this is the right approach to the acquisition of learning which has to do with values, beliefs, attitudes, social relations, emotional adjustments, habits and life styles. While the desire of every nation is having good citizens in increasing number, paradoxically, a major means of attaining this is the teaching and assessment of affective characteristics which is not receiving the necessary attention in online education.

Even with the focus on the cognitive domain, online education programs are still producing many students that fall short in this area. The biggest critics of today's educational system are the business community and those who have graduated from inclass education and or online education programs. Though many of them also passed through both or either of the educational programs, they can now see that the programs are not actually giving those passing through them what it takes to actually perform excellently out there in the wider world. As Griffith \& Nguyen (2006) pointed out, what good is the acquisition of a vast range of academic skills if we are unable to integrate them? They observe that students need to be able to communicate value, organize and characterize, to effectively utilize and make sense of what they have learnt. These however are affective characteristics. This being the case, it is extremely difficult, if not totally impossible to attain maximally in the cognitive domain in online education unless the complementary skills in the affective domain are well taught and carefully developed.

Sumsion \& Goodfellow (2004) in their work mapping generic skills across a number of curriculums articulated their concerns with what they describe as "unproblematised accounts of the development of generic skills and qualities" (p330). They claim that 
the skills that one might develop in an environment such as in a Higher Education setting might not automatically transfer to other settings. Furthermore, they assert that there is a difference between capacity and competence such that "—capacity extends beyond competence; it involves an ability and a willingness to apply understanding, knowledge and skills to unfamiliar contexts and unfamiliar problems (p.332). Precisely, the argument is that while cognitive skills may be developed well enough in the university through in-class, online or blended form of learning, unless the student has certain affective capabilities they are less likely to be able to use their cognitive skills and understanding across a range of environments (Boud \& Falchikov,2006). Consequently, there must be an explicit relationship between cognitive learning, assessment and "capability" (Sumsion \& Goodfellow, 2004).

Crebert, Bates, Bell, Patrick \& Cragnolini (2004) claimed that a student's ability to integrate and demonstrate generic skills across contexts "Requires ethics, judgment and self confidence to take risks and a commitment to learn from experience" (p.148). "The idea of skills, even generic skills is a cull de sac. In contrast, the way forward lies in construing and enacting pedagogy for human being. In other words, learning for an unknown future has to be understood neither in terms of knowledge nor skills but of human qualities and dispositions". (Barnett, 2004, p.247). In 'Learning for an unknown future' Barnett (2004) states that a being capable of thriving with uncertainty needs dispositions; "Among such dispositions are carefulness, thoughtfulness, humility, criticality, receptiveness, resilience, courage and stillness" (p.258). The reality of the submissions of Crebert et al \& Barnet can be seen in the common cases of graduates from online education programs with certificates showing brilliant academic attainments but who cannot deliver in the society.

The cognitive and the affective domains are interdependent. For this reason, focusing on cognitive constructs to the exclusion of affective construct in online education can only unavoidably lead to an incomplete educational experience for online learners and this has been the situation in online education for some time. The implication of this among other things is that we have online learners for example with an advanced knowledge of their specific fields and with great abilities but with little or no regard for their professions or the ethical standards that govern them. Educators can only foster the desired positive change in learners' dispositions, attitudes, values and ethical perspectives by obtaining necessary information through a diligent and consistent assessment of the affective domain. Incidentally this is the domain that has been left dormant for some time now in online education. The essence of assessing dispositions is to ensure that the learners have positive attitudes, values, etc so that online educators can capitalize on these, work on them to bring about increase attainment on the part of online learners. Where the assessment reveals negative feelings, the onus is on the 
online educators to labor for necessary educational experiences that will bring about the anticipated positive dispositions.

Krathwol, Bloom \& Masia (1964, p.60) in their seminal work described the affective domain by contrasting it with the cognitive domain thus: "In the cognitive domain we are concerned that the student shall be able to do the task when requested. In the affective domain we are more concerned that he does do it when it is appropriate after he has learned he can do it" Krathwohl's definition is shows that the emphasis in the affective domain is : "did you" or didn't you" when you knew how? With this definition the problem of subjectivity is totally ruled out. Birbeck (2008) gave a practical application of Krathwohl's distinction within the traditional classroom set up when he writes: "I once taught Ethics to fourth year Education students. The final assessment asked the students to discuss their understanding of ethics and they were encouraged to use examples from their experiences on preceding practicum placements. One student wrote about how he came to believe that a student in his year two class had been sexually abused. He reported the matter to his mentor teacher and his ethical discussion in his essay centered on the fact that to his knowledge the teacher did not comply with South Australian law in terms of mandatory notification. What was not covered in the essay was that the student had completed his mandatory notification training and was under an equally compelling obligation as his mentor teacher to notify. Arguably, he had a higher obligation as it was his conviction of the abuse that raised the issue. ----He could have reported but he did not-----he has not demonstrated that he has the capacity to protect his students; an expectation placed on his profession by society, his employer and by his profession".

Applying Krathwohl, Bloom \&Masia (1964) description in online education enables one to judge an outcome in the affective domain without necessarily occupying the untenable position of judging another's attitude, values, feelings or motivations. The judgment is carried out by aligning the student's actions with what is expected by the particular profession in question. It is important to ensure that those receiving education online not only acquire knowledge but also the willingness to do what is expected of their respective professions when it is appropriate. This problem however would be taken care of once the teaching and assessment of affective characteristics are given the necessary attention in online education.

\section{The Way Forward}

For online students to be rest assured that they are in the right hands and for stake holders to be guaranteed that online teachers are doing the right things pedagogy wise, it will be necessary for the relevant authorities at national and or international level to 
agree on what should be regarded as adequate professional training and to insist on this.

It is important to ensure that the whole process of online teaching and learning is standardized and the standard maintained through internal and external moderation mechanisms. Such internal and external moderation of all aspects of online education should not be a one-time exercise but something that is made on-going at very regular and very specific intervals with documented reports for record purposes. In addition, the establishment of an accrediting body will go a long way in ensuring that standards are attained and maintained in online education. Such a body saddled with the accreditation of all programs that are to go online could be at national and international levels and the accreditation should not be a one-time exercise. Accreditation should be given for a reasonably short period of time, at the expiration of which there will be the examination and assessment of programs and facilities again in order to be accredited for another given period. This obviously is cumbersome but it will safeguard the system from becoming simply another way for institutions to make more money and another way for some individuals to get cheap diplomas conveniently to the detriment of the larger society

To further allay the fears of the public about online education, it is suggested that those interested in training as online educators be given the opportunity of receiving adequate training to teach online as part of their basic and initial teacher preparation. In other words, initial teacher education programs should be designed to prepare the trainee teachers for both face to face teaching and online teaching. This may warrant an increase in the duration of Teacher Education program in order to ensure that the training given to teacher trainees is thorough.

Those who are currently teaching online and have not received formal professional training at all or in the special area of online teaching should be mandated to do so within a particular time frame if they are still interested in the job. An established fact of online teaching is that it takes a lot more time and effort than traditional classroom instruction. This being the case, it is suggested that remuneration that is commensurate with the challenging workload of online teaching be offered to online teachers in order to attract and retain the best of teachers and to motivate the best of teachers to give their very best, work conscientiously, be mindful of quality and stay on the job instead of migrating to greener pastures. A commensurable remuneration will also encourage the teachers to go for the necessary professional training that will keep them on the job.

Moreover, going by the implications of this continued neglect of the affective domain in favor of the cognitive domain in online education as pointed out in this paper, There is need for a coordinated and comprehensive move to restore the needed balance. In 
doing this, it is important to note that certain teaching and learning activities can be very helpful. These activities include: problem based learning, group analysis of case studies, perspective sharing and reflection, appropriate use of multimedia to trigger responses. These activities, if well handled and integrated into online programs by the educators, will go a long way in fostering the teaching and assessing of affective characteristics.

The measurement of important personal and social qualities such as those in the affective area cannot be captured directly as done in the measurement of height and weight which involves the use of well calibrated and standardized tools that directly measure stable qualities. The measurement of temperament, personality, attitudes, feelings, emotions, and values may involve the use of tools that are not as well calibrated. However, in overcoming these and similar problems in online education, some of the methods that could be adopted include: the use of observations, interviews, self-report, questionnaires and surveys. Measurement generally is enhanced when data from various informed and knowledgeable sources is considered. For example, when working with adolescents, measurement of important affective traits may be enhanced by acquiring information directly from the target adolescents as well as from their parents and siblings, teachers, friends and other peers, together with others who are very close to them. The acquisition of information from other sources may be particularly beneficial when the traits being measured are displayed externally (as opposed to ones like preferences that are displayed internally). The qualities being assessed are less reliable (e.g. moods), and the psychometric properties of the measures are weak. The availability of information from various sources will enable online educators to determine its completeness and consistency.

Furthermore, an accurate understanding of one important trait is enhanced by information about various other important traits. For example, an understanding of qualities associated with extroversion-introversion generally is enhanced by knowledge of a person's age, gender, intelligence, achievement, language, self concept, and other important qualities.

It would also serve a very good purpose if online educators are given grants by relevant authorities to organize regular conferences, workshops and in-service training in the area of affective characteristics and their assessment with the outcome of such exercise strategically and wisely disseminated. Some of the issues that online educators may focus upon are:

- What methods of affective education would be legitimate to adopt in a situation where young online learners do not have the capacity to think logically at higher cognitive levels? 
- What happens if genuinely and carefully formulated values and actions go contrary to established values and traditions of Institutions offering online programs?

- What public value may be promoted within the scope of the law such that the rights of online learners and the rights of the society will both be protected?

These and many other issues about affective education and affective assessment can definitely not be sorted out in one go. However the journey towards solution must start actively and in a coordinated and comprehensive way somewhere. If this is done, before long, the needed balance between affective and cognitive domains will be restored and online educational experience will be complete and rewarding.

\section{Conclusion}

The strengths of online education are enormous. These however must be protected. One of the ways of doing this is for the relevant authorities to acknowledge the emanating issues and challenges of the innovative system and avail themselves of the various suggested solutions by taking practical steps. With the commitment to perfect online education, the various emanating challenges would be turned into opportunities and the educational experience would become a complete and rewarding one.

\section{References and Notes:}

Allen, I.E. \& Seaman, J. (2008). Sizing the opportunity: The quality and extent of Online Education in the United States, 2002 and 2003. The Sloan Consortium, Needham, Massachusetts. Retrieved. February 12, 2004 from http//www.sloan -.org

Allen,E.I. \& Seaman, J.(2003). Entering the Mainstream: The Quality and extent of Online education in the United States(Needham, Mass,:The sloan Consortium, 2004) and T.M.Olson and R.A Wisher, "The effectiveness of We-Based Instruction: An Initial Inquiry, International Review of Distance Learning. Vol3,No 2, 2002.

Aragon, S. \& Johnson, E. (2008). Factors influencing completion and non completion of Community College Online Courses. American Journal of Distance Education, 22(3), 148-158. Retrieved from ERIC database.

Barnett, R. (2004). Learning for an unknown future. High Education Research and Development, 23, 247-260.

Barnett, R. (2004). Learning for an unknown future. High Education Research and Development, 23 (3), $247-260$.

Birbeck, D. \& Andre, K. (2009), The affective domain: beyond simply knowing, ATN Conference, RMIT University.

Birbeck, D. (2009). Graduate qualities and the affective domain:New Horizons to explore. Adelaide University of South Australia. 
Bloom, B.S, Engelhart, M.D, Furst, E.J, Hill, W.H, \& Krathwohl, D.R (Eds). (1956). Taxonomy of educational objectives; The classification of educational goals. Handbook I; The cognitive domain. New York; David McKay Co Inc.

Bonnet, G. (2007). "What do recent evaluations tell us about the state of Teachers in SUB Saharan Africa" A background paper prepared for the Education for All by 2015: Will we make it-The paper was commissioned by Education for All Global Monitoring report as background information to assist in drafting the 2008 report.

Boud, D. \& Falchikov, N. (2006). Aligning assessment with long term learning. Asessment and evaluation in Higher Education, 31(40, 399-413).

Capra, T.(2011). Online Education: Promise and problems. Merlot Journal of Online Learning and Teaching. Vol 7 No 2 June.

Callopy, R. \& Arnold, J. (2009). To Blend or Not to Blend: Online and Blended Learning Environment in undergraduate Teacher Education, Issues in Teacher Education, 18(2), 85-101. Retrived from ERIC database.

Colby, A, \& Sullivan, W.M.(2009).Strengthening the foundations of students 'excellence, integrity, and social contribution, Liberal Education,95(1)22-29.

Duncan, H., \& Barnett, J. (2009). Learning to Teach Online: What works for Pre Service Teachers. Journal of Educational Computing Research. 40(3), 357-376. Retrieved from ERIC data base.

Ebersole, J.F. (2007). Online Education: Advancing the Learning Curve. The New York Times. PA21

Gibbs , G. \& Coffey, M. (2004). "The impact of training of University Teachers on their Teaching Skills, their approach to teaching and their approach to learning of their students."Active Learning in Higher Education" 5(1):87 -100.

Griffith, G.K. \& Nguyen, D.A. (2006). Are Educators Prepared to Affect the Affective Domain? National Forum of Teacher Education, Journal-Electronic. Volume 16 Number 3E, 2005-2006.

Ingersoll, R.M, \& Perda, D. (2008). The Status of Teaching as a Profession. P106-118 in Schools and Society: a Sociological Approach to Education. Edited by Jeanne Ballantine and Joan Spade. Los Angeless: Pine Forge Press.

Krathwohl, D.R., Bloom, B.S. \& Masia, B.B. (1964). Taxonomy of Educational Objectives: Handbook 2: The Affective Domain, London, Longman, Green and Co Ltd.

Keengwe, J., Kidd, T.T, \& Kye-Blackson, L (2009). Faculty and Technology:Implications for faculty training and technology leadership. Journal of Science Education and Technology. 18(1),23-28.

Levine, A. \& Sun, J.C. (2003). Barriers to distance education. Washington, DC:American Council on Education.

Nolting, P. (2007). Winning at math $\left(5^{\text {th }}\right)$ Bradenton, FL: Academic Success Press Inc.

Olubor, R.O. \& Ogonor, B.O. (2007). Instructional activities of Staff personnel in the affective domain in selected secondary schools in Southern Nigeria. International Education Journal, 8(1), 82-88.

Popham, W.J. (2011 ). Classroom Assessment: What teachers need to know. Boston, M.A: Pearson. 
Saxon, P. \& Calderwood, B.(2008). Affective Assessment for Developmental Students, Part 1.Research in Developmental Education. Vol. 22, Issue 1, 2008. Appalachian State University.

Shephard, K, (2009). Higher education for sustainability: Seeking affective learning outcomes. International Journal of Sustainability in Higher Education, 9(1), 87-98.

Shepherd, C.(2008). Increasing the efficacy of Educators Teaching Online. International Journal of Social Sciences. Vol. 2 No3.

Stiggins, R.J. (2005). Student-invovled assessment for learning. Upper Saddle River, NJ: Pearson.

Sumsion, J, \& Goodfelow, J, (2004). Identifying generic skills through curriculum mapping:a critical evaluation. High Education Research and Development, 23(3), 329-346.

Swenson, C. (2007). The digital divide: 19 th century classroom, $21^{\text {st }}$ century learners. Distance Learning Today, 1(2) 6.

Talent, R, Copper, M, Lan, S, Thomas, W. Bushy, C.(2005). How to teach online: What the research says, Distance Learning, Vol.2(1) p21-28.

\section{Summary}

\section{Online Education: Issues, Challenges and Implications}

\section{OLATUNJI, Michael Olalekan}

\section{Institute of Educational Leadership, Gaborone, BOTSWANA}

Swenson (2007) observed that "in the space of one brief decade, the internet has changed our world and most of us with it". He remarked further that our ways of doing things are different now as a result of digital revolution in education. To be successful therefore in a $21^{\text {st }}$ century world, in which knowledge is generated at an ever increasing pace, requires that learning be made an ongoing process of skill development and knowledge creation. Online education programs are a reflection of this new world as they offer education without borders (Levine \& Sun, 2003). Online education has experienced dramatic expansion while institutions of higher learning continue to increase online course offerings in an effort to satisfy student demand (Capra, 2011). However, Capra submitted further that, while this growth is impressive, it is not without unintended negative consequences. As a result of the increasing import of online education over the years, attempt is made in this paper to examine some of the negative consequences inherent in this innovative form of education which one sees as issues and challenges. The paper also discusses the implications of the identified issues and challenges with strategic suggestions made as to the way forward

Key words: Pedagogy, in-class, professional training, affective, cognitive, online educators. 